\title{
PEMBERIAN MASSAGE PUNGGUNG TERHADAP KLIEN HIPERTENSI DI KOTA BANDAR LAMPUNG
}

\author{
M. Ricko Gunawan ${ }^{1}$, Evi Marta², Rahma Elliya ${ }^{3^{*}}$ \\ ${ }^{1,3}$ Dosen Program Studi Ilmu Keperawatan Universitas Malahayati \\ ${ }^{2}$ Mahasiswa Program Profesi Ners Universitas Malahayati \\ Email Korespondensi :muhrickogunawan@gmail.com
}

\begin{abstract}
ABSTRAK
Badan Kesehatan Dunia (WHO) menyebutkan jumlah penderita hipertensi akan terus meningkat seiring dengan jumlah penduduk yang bertambah pada 2025 mendatang diperkirakan sekitar 29\% warga dunia terkena hipertensi. Untuk membuat tubuh menjadi rileks dapat dilakukan dengan beberapa cara seperti terapi musik klasik, yoga, tehnik nafas dalam, dan terapi massage untuk menurunan hipertensi. Tujuan setelah penyuluhan dan demonstrasi, diharapkan pemberian massage punggung dapat untuk tekanan darah pada klien hipertensi. Adapun kegiatan yang dilakukan berupa penyuluhan menggunakan leaflet dan demonstrasi massage punggung. Terdapat penurunan tekanan darah pada klien hipertensi setelah pemberian massage punggung selama 7 hari di bandar lampung. Dengan demikian, pemberian massage punggung pada klien hipertensi sangat efektif dalam menurunkan tekanan darah.
\end{abstract}

Kata Kunci: massage punggung, hipertensi

\begin{abstract}
The World Health Organization (WHO) said the number of people with hypertension will continue to increase along with the population increasing in the next 2025 estimated that around 29\% of world citizens affected by hypertension. To make the body relaxed can be done in several ways such as classical music therapy, yoga, deep breathing techniques, and massage therapy to reduce hypertension. The purpose after counseling and demonstration, it is hoped that back massage can be used for blood pressure in hypertensive's client. The activities carried out in the form of counseling using leaflets and demonstrations of back massage. There was decrease in blood pressure in hypertensive's client after giving back massage for 7 days at Bandar Lampung. Thus, giving back massage to hypertensive clients is very effective in lowering blood pressure.
\end{abstract}

Keywords: back massage, hypertension 


\section{PENDAHULUAN}

Badan Kesehatan Dunia (WHO) menyebutkan jumlah penderita hipertensi akan terus meningkat seiring dengan jumlah penduduk yang bertambah pada 2025 mendatang diperkirakan sekitar 29\% warga dunia terkena hipertensi. WHO menyebutkan negara ekonomi berkembang memiliki penderita hipertensi sebesar $40 \%$ sedangkan negara maju hanya $35 \%$, kawasan Afrika memegang posisi puncak penderita hipertensi, yaitu sebesar 40\%. Kawasan Amerika sebesar 35\% dan Asia Tenggara 36\%. Kawasan Asia penyakit ini telah membunuh 1,5 juta orang setiap tahunnya. Hal ini menandakan satu dari tiga orang menderita hipertensi. Sedangkan di Indonesia cukup tinggi, yakni mencapai 32\% dari total jumlah penduduk (Widiyani, 2013; Almiyani, 2018).

Riskesdas 2018 menyatakan prevalensi hipertensi berdasarkan hasil pengukuran pada penduduk usia $\geq 18$ tahun sebesar $34,1 \%$, tertinggi di Kalimantan Selatan (44.1\%), sedangkan terendah di Papua sebesar (22,2\%). Estimasi jumlah kasus hipertensi di Indonesia sebesar 63.309.620 orang, sedangkan angka kematian di Indonesia akibat hipertensi sebesar 427.218 kematian.

Hipertensi terjadi pada kelompok umur 31-44 tahun (31,6\%), umur 45-54 tahun (45,3\%), umur 55-64 tahun $(55,2 \%)$. Dari prevalensi hipertensi sebesar $34,1 \%$ diketahui bahwa sebesar 8,8\% terdiagnosis hipertensi dan $13,3 \%$ orang yang terdiagnosis hipertensi tidak minum obat serta $32,3 \%$ tidak rutin minum obat. Hal ini menunjukkan bahwa sebagian besar penderita Hipertensi tidak mengetahui bahwa dirinya Hipertensi sehingga tidak mendapatkan pengobatan (Riskesdas RI, 2018).

Hipertensi yang tidak mendapat penanganan yang baik menyebabkan komplikasi seperti Stroke, Penyakit Jantung Koroner, Diabetes, Gagal Ginjal dan Kebutaan. Stroke (51\%) dan Penyakit Jantung Koroner $(45 \%)$ merupakan penyebab kematian tertinggi.Kerusakan organ target akibat komplikasi Hipertensi akan tergantung kepada besarnya peningkatan tekanan darah dan lamanya kondisi tekanan darah yang tidak terdiagnosis dan tidak diobati. Organ-organ tubuh yang menjadi target antara lain otak, mata, jantung, ginjal, dan dapat juga berakibat kepada pembuluh darah arteri perifer itu sendiri. Selain itu Hipertensi banyak terjadi pada umur 35-44 tahun (6,3\%), umur 45-54 tahun (11,9\%), dan umur 55-64 tahun $(17,2 \%)$. Sedangkan menurut status ekonominya, proporsi Hipertensi terbanyak pada tingkat menengah bawah $(27,2 \%)$ dan menengah $(25,9 \%)$ (Kemenkes RI, 2019).

Pengobatan hipertensi ada dua jenis yaitu dengan farmakologis dan non farmakologis. Pengobatan farmakologis dalam jangka panjang bahkan seumur hidup, dapat diberikan seperti diuretik, betabloker dan vasodilator (Wulandari, 2010). Obat kimia deuretik memiliki kelebihan yaitu mempunyai ketepatan dalam dosis karena dibuat zat aktif, akan tetapi, kelemahannya adalah memiliki efek samping yang lebih besar dibandingkan dengan terapi non farmakologi. Selain itu, harganya pun mahal, hal ini disebabkan karena bahan bakunya masih didatangkan dari luar negri (Triyanto, 2014). Terapi relaksasi diperlukan pada penderita hipertensi agar membuat pembuluh darah menjadi relaks sehingga akan terjadi vasodilatasi yang menyebabkan tekanan darah kembali turun dan normal. Untuk membuat tubuh menjadi relaks dapat dilakukan dengan beberapa cara seperti terapi musik klasik, yoga, teknik nafas dalam, dan terapi 
masase (Suarni, 2019) Sejumlah studi menunjukkan bahwa terapi masase/pijat yang dilakukan secara teratur dapat menurunkan tekanan darah sistolik dan diastolik, menurunkan kadar hormone stress cortisol, menurunkan kecemasan sehingga tekanan darah akan turun dan fungsi tubuh semakin membaik (Churniawati, Martini, \& Wahyuni, 2016)

Relaksasi merupakan tindakan yang harus dilakukan pada setiap terapi antihipertensi. Apabila tekanan darah terlalu tinggi, pembuluh darah yang relaks akan terjadi vasodilatasi pembuluh darah sehingga akan menyebabkan tekanan darah turun dan kembali normal. Untuk membuat tubuh menjadi rileks dapat dilakukan dengan beberapa cara seperti terapi musik klasik, yoga, tehnik nafas dalam, dan terapi masase (Suarni, 2019).

Massase refleksi adalah pijat dengan melakukan penekanan pada titik syaraf di kaki, tangan atau bagian tubuh lainnya untuk memberikan rangsangan bio-elektrik pada organ tubuh tertentu yang dapat memberikan perasaan rileks dan segar karena aliran darah dalam tubuh menjadi lebih lancar (Trionggo, 2013). Apabila pembuluh darah yang relaks akan terjadi vasodilatasi pembuluh darah sehingga akan menyebabkan tekanan darah turun dan kembali normal. Untuk membuat tubuh menjadi relaks dapat di lakukan dengan beberapa cara seperti terapi musik, tarik nafas dalam, dan terapi masase (Muttaqin, 2009). Terdapat beberapa teknik terapi masase yang dapat dilakukan yaitu: masase leher, masase kepala, masase kaki, dan masase punggung (Saputro, 2013)

\section{MASALAH}

Alasan saya memilih tempat penyuluhan kesehatan tentang Hipertensi dan demontrasi tentang pemberian massage punggung di Bandar Lampung ialah karena keluarga saya sendiri memiliki masalah kesehatan hipertensi. dimana tujuan umum dalam kegiatan diharapkan pemberian massage punggung dapat menurunkan tekanan darah pada klien hipertensi. Dan tujuan khusus dalam kegiatan yaitu asuhan keperawatan, telaah jurnal untuk menentukan intervensi, evaluasi hasil aplikasi intervensi, perbandingan hasil intervensi pemberian massage punggung.



Gambar 2.1 Lokasi penyuluhan dan demonstrasi 


\section{METODE}

1. Tujuan Persiapan

Tahap persiapan dari kegiatan adalah pembuatan pre planning, persiapan penyajian leaflet dan demostrasi, tempat dan alat-alat lainnya disiapkan oleh peneliti. Pembuatan leaflet dibuat pada hari selasa 06 Mei 2020, pada tanggal 07 Mei 2020 dilakukan penyuluhan, pengecekan tekanan darah, dan demostrasi massage punggung.

2. Tahap Pelaksanaan

Kegiatan ini dengan pemberitahuan kepada klien. Dan dilanjutkan penyuluhan penyuluhan, pengecekan tekanan darah, dan demostrasi massage punggung.

3. Evaluasi

a. Struktur

Peserta hadir 1 orang yaitu perempuan. Setting tempat sudah sesuai dengan rencana dan perlengkapan yang dilakukan untuk penyuluhan sudah tersedia dan sudah digunakan sebagaimana mestinya. Peran peneliti sebagai modertor, notulen, observer, dan juga fasilitator. Penggunaan bahasa yang dipraktekkan sudah komunikatif dalam penyampaianya, klien dapat memahami dan dapat mempraktekkan kembali yang di demonstrasikan.

b. Proses

Pelaksanaan kegiatan dilaksanakan pukul $09.00 \mathrm{~s} / \mathrm{d} 09.30 \mathrm{WIB}$. Sesuai dengan jadwal yang sudah ditentukan.

c. Hasil

1. Klien dapat memahami dan mengerti tentang pengertian terapi massage punggung

2. Klien dapat memahami dan mengerti tentang tujuan dilakukannya terapi massage punggung

3. Klien dapat memahami dan mengerti tentang manfaat dan teknik pembuatan terapi massage punggung

4. Klien dapat memahami dan mengerti tentang langkah-langkah massage punggung 


\section{HASIL DAN PEMBAHASAN}

Pelaksanaan pemberian terapi massage punggung dilaksanakan pada tanggal 07 Mei 2020 s/d 13 Mei 2020. Penelitian dilakukan selama 7 hari, setelah dilakukan nya pemberian terapi selama 7 hari menurunkan tekanan darah klien. Berikut gambar pelaksanaan penyuluhan, pengecekan tekanan darah dan pemberian terapi massage punggung:
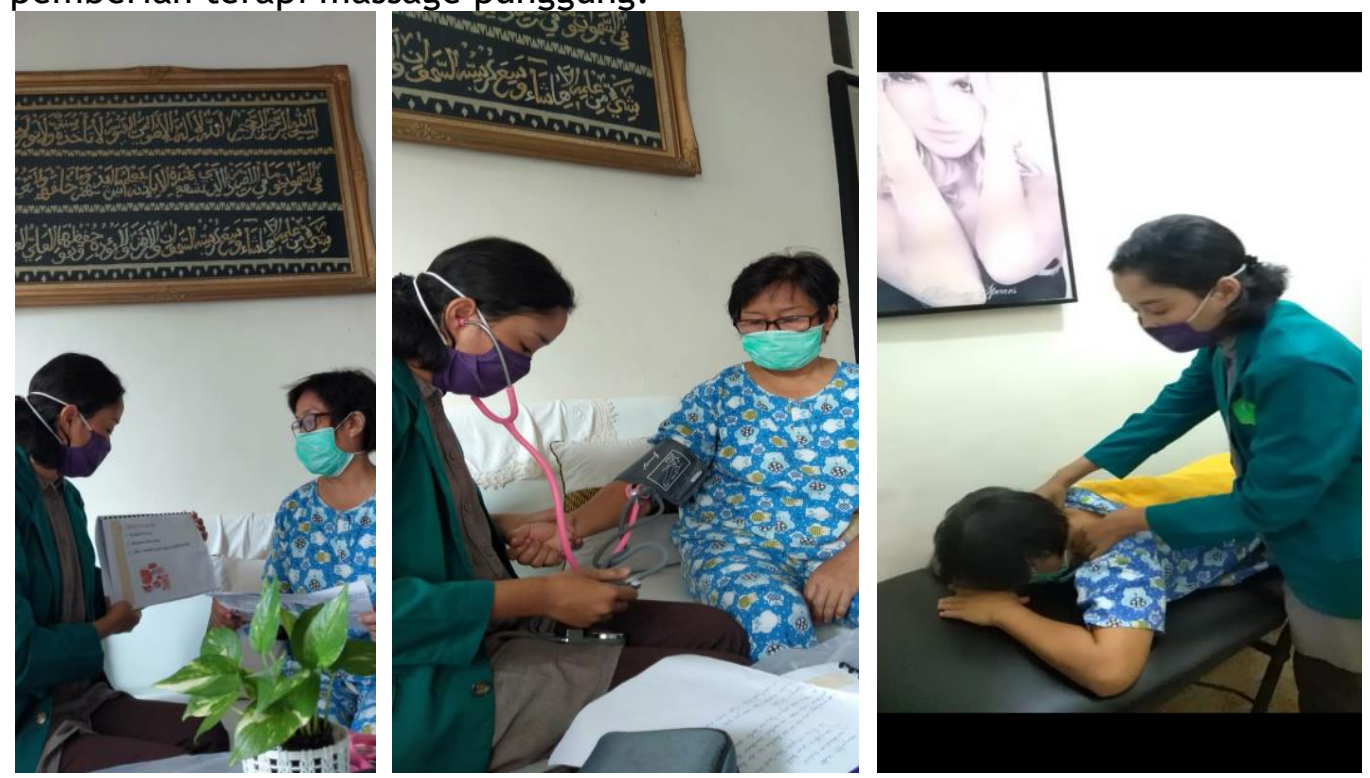

Gambar 4.1 pelaksanaan penyuluhan massage punggung, pengecekan tekanan darah, dan pelaksanaan terapi massage punggung

\section{KESIMPULAN}

Terapi non farmakologi pemberian massage punggung terbukti dapat menurunkan tekanan darah pada penderita hipertensi. Hal ini membuktikan beberapa hasil penelitian yang pernah dilakukan kepada klien dengan hipertensi, bahwa pemberian massage punggung dapat dijadikan alternatif perawatan hipertensi yang murah, mudah, dan aman.

\section{DAFTAR PUSTAKA}

Anies. (2018). Penyakit Degeneratif. Ar-Ruzz Media: Yogyakarta.

Dinkes Kota Bandar Lampung. (2019). Kejadian Hipertensi.

Indrayani., Maudy. (2016). Asuhan Persalinan dan bayi Baru Lahir. Jakarta: CV Trans Info.

Kemenkes RI. (2015). Pengertian Hipertensi.

Kemenkes RI. (2019). Kejadian Hipertensi. Jakarta: Indonesia.

Majid, A. (2019). Asuhan Keperawatan Pada Pasien Dengan Gangguan Sistem Kardiovaskular. Pustaka Baru: Yogyakarta.

Manurung, N. (2016). Aplikasi Asuhan Keperawatan Sistem Kardiovaskuler. Trans Info Media: Jakarta.

Maryunani. (2010). Nyeri Dalam Persalinan "Teknik dan Cara Penanganannya". Jakarta, Trans Info Media. 
Riskesdas RI. (2018). Kejadian Hipertensi. Jakarta: Indonesia.

Saferi, AW. (2019). KMB 2 Keperawatan Medikal Bedah (Keperawatan Dewasa). Trans Info Media: Jakarta.

Sukardin, Dkk. (2018). Pengaruh Pemberian Masase Punggung Dan Relaksasi Nafas Dalam Terhadap Penurunan Tekanan Darah Pada Lansia Hipertensi Di Balai Sosial Lanjut Usia (BSLU) Mandalika Provinsi NTB. STIKES Mataram

Yekti, Susilo dr. (2020).Cara Jitu Mengatasi Hipertensi. Andi Ofset: Yogyakarta.

Yanti, Etri., dkk. (2018). Efektifitas Massase Punggung Dan Kaki Terhadap Tekanan Darah Pada Penderita Hipertensi. STIKES Syedza Saintika Padang

Wijayanto, Tri. (2017). Pengaruh Terapi Masase Menggunakan Minyak Aroma Terapi Terhadap Tekanan Darah Pasien Hipertensi Primer. STIKes Muhammadiyah Pringsewu. 